\title{
As favelas como territórios de reinvenção da cidade
}

\author{
Jorge Luiz Barbosa ${ }^{1}$ \\ Jailson de Souza e Silva²
}

\begin{abstract}
Resumo
O presente artigo busca analisar as formas como as favelas são representadas no âmbito da cidade e como é possível percebê-la a partir de suas condições de território constituinte do urbano e como um "problema", "desvio" ou expressão da "anti-cidade". O reconhecimento, portanto, de suas potências é uma premissa central para que os moradores das favelas possam afirmar plenamente sua condição de sujeito de direitos e, portanto, à cidade".
\end{abstract}

Palavras-chave: favelas; cidade; identidade; representações territoriais.

\begin{abstract}
This article seeks to analyze the ways in which favelas are represented within the city and how it possible to perceive it from their condition of being a constituent in-urban territory and a "problem", "deviation" or expression of "anti-city". The recognition, therefore, of their potentials is a central premise for that favela dwellers can fully assert their status as subjects of rights and therefore of rights to the city.
\end{abstract}

Key words: favela; city; identity; territorial representations.

Toda casa é uma árvore

Que no corpo se enraíza

$\mathrm{O}$ universo tem começo

No chão que se habita (Adriano Espínola, Fala Favela)

\section{Introdução}

A presença cada vez mais significativa de favelas no processo de produção da metrópole do Rio de Janeiro vem se impondo, notadamente, como uma das mais relevantes temáticas da urbanização do território. Ao se afirmar na paisagem urbana, a

\footnotetext{
${ }^{1}$ Geógrafo; Coordenador do Programa da Pós-graduação de Geografia da Universidade Federal Fluminense; Diretor do Observatório de Favelas.

${ }^{2}$ Geógrafo; Professor da Faculdade de Educação da Universidade Federal Fluminense; Diretor do Observatório de Favelas.
} 
favela se torna um fenômeno em questão para a sociedade, exigindo o desvelamento de seu sentido social, político e territorial.

Estudos clássicos como os de PARISSE (1969); LEEDS, Anthony \& LEEDS, Elisabeth (1978); PERLMAN (1980); ZALUAR (1980); VALLADARES (1980) e SANTOS (1982) demonstraram a intensa e diversa vida cotidiana das favelas em sua imersão nas contradições e conflitos de uma cidade-metrópole como a do Rio de Janeiro. As obras citadas fazem parte de uma linhagem de estudos de sociologia urbana, que contribuíram para retirar as favelas do anonimato da metrópole e da condição de subproduto indesejável da urbanização brasileira, revelando a sua complexidade social e urbana.

Sob a influência das obras pioneiras supracitadas emergiram estudos importantes, que passaram a elaborar leituras das favelas, a partir de determinados eixos temáticos: Educação (Victor Valla, 1986); Habitação (Lia de Aquino Carvalho, 1995; Sergio B. Perdigão, 1999); Cultura (Marcos Alvito, 2000); Violência (Alba Zaluar, 1998). Além do destaque temático, as obras citadas focalizaram favelas consideradas como representativas de determinados acontecimentos, demarcando uma preocupação acentuada, sobretudo nas décadas de 1980 e 1990, de estudos particularizados em favelas na cidade do Rio de Janeiro.

Não há dúvidas de que os estudos temáticos, assim como os realizados em localidades específicas, abriram universos relevantes para o entendimento das favelas como fenômeno multifacetado e das individualidades dos espaços populares face às leituras reificadas do senso comum e da retórica conservadora dos meios de informação de massa. Das possibilidades abertas com os estudos temáticos e os de perfil mais localizados, outros esforços de pesquisa surgiram com o objetivo de colocar em evidência a relação favela / cidade no conjunto próprio das tensões urbanas, superando a leitura limitada de cidade partida em voga nos discursos recorrentes da exclusão urbana. Chamamos atenção para as obras A Invenção da Favela de Lícia Valladares (2006), Favelas Cariocas, de Maria Laís Pereira da Silva (2005) e Favela, alegria e dor na cidade (2005), de Jailson de Sousa e Silva e Jorge Luiz Barbosa, como as mais representativas desse movimento de tessitura crítica da favela com a cidade.

Retomamos o viés contemporâneo de superação de leituras das favelas em si, como contribuição para a compreensão das favelas para si na cidade. Caminho que implica a percepção da favela como componente da cidade, mas com a própria história 
da cidade e de seu devir. Para tanto, é decisivo compreender esses territórios em seu processo constitutivo e das diferenças que abrigam cada comunidade popular urbana. Apreciá-las em seu movimento de realização na cidade - combinando suas dimensões objetivas e subjetivas - nos permite reconhecer a complexidade, diversidade e conflitos da própria urbanização da sociedade brasileira.

\section{A favela é cidade: um debate na perspectiva do território usado}

A cidade é a construção coletiva do compartilhar de percepções, concepções e experiências de mundo. Resultado da ação de vínculos das relações sociais com a natureza, a cidade é um espaço de encontro e constituição das diferenças. Nesta perspectiva podemos afirmar que a cidade é uma criação humana territorialmente impressa. É a sociedade, ganhando conteúdo e forma, em uma dimensão concretosimbólica particular. É por isso que, quando falamos na relação sociedade / cidade, devemos reportar a relação ator /território. Seja esse ator um indivíduo, um grupo, uma comunidade, uma classe, uma empresa ou instituição social, eles estarão envolvidos entre si por sua inscrição territorial.

Diferentes territórios são produzidos no espaço urbano segundo as práticas, vivências e experiências dos seus atores. Esses territórios se sobrepõem e são contínuos ou radicalmente distintos, existindo em diferentes movimentos, que definem a forma e o conteúdo de seu uso. Como afirma Milton Santos (2000), o território em si não é um conceito, tornando-se tal apenas a partir de seu uso social. O território somente se constituiria num conceito utilizável para análise, quando fossem considerados os atores que dele se utilizam e fazem sua experiência concreta de ser no mundo.

Definido pelo citado autor como a união dos sistemas naturais e históricos materiais, o território seria formado pelo "conjunto indissociável do substrato físico, natural ou artificial, e mais o seu uso, ou em outras palavras, a base técnica e mais as práticas sociais, isto é, uma combinação de técnica e de política" (SANTOS, 1999, p. 5). Assim, território ultrapassa a concepção político-administrativa, meramente formal e ganha a dimensão de um espaço socialmente demarcado pelas ações e intenções de sujeitos sociais. O território significa, portanto, a constituição necessária de laços que se definem pela apropriação e uso das condições materiais e também dos investimentos simbólicos, estéticos e éticos, que revelam o sentido da própria sociedade instituída. 
Pertencemos a um território, o guardamos, o habitamos e nos impregnamos dele ao realizar nosso modo de existir.

Essa proposta de abordagem reporta-se ao conceito de território usado, que se "constituiria de um todo complexo, onde se tece uma trama de relações complementares e conflitantes" (SANTOS, 2000:2). O conceito de território usado permite pensar as relações existentes entre o lugar, a formação socioespacial e o mundo, sendo tanto resultado do "processo histórico, quanto da base material e social das novas ações humanas" (SANTOS, 2000:1). É assim que é no território que se faz possível reconhecer o sentido dos interesses coletivos, promover pertencimentos e de mobilizar forças plurais de mudança. O território significa, portanto, uma marca e uma matriz daquilo que verdadeiramente somos e do que queremos para as novas gerações de cidadãos.

Colocar as favelas na perspectiva de uma leitura do território usado significa chamar atenção para os sujeitos sociais em suas práticas de construção do mundo da vida, do território como morada dos afetos, dos trajetos, dos saberes, dos sabores, dos fazeres de homens e de mulheres concreto(a)s em suas paixões, dramas e sonhos.

\section{As Favelas como Representação e Experiência Urbana}

As favelas sempre foram consideradas, nos discursos hegemônicos, como territórios da ausência da civilidade e da urbanidade. A obediência ao senso comum fez com que o IBGE definisse, desde o Censo de 1990, as favelas como "aglomerados subnormais", termo que ratifica o conteúdo conceitual historicamente utilizado. Por outro lado, as condições físicas de moradas nas favelas também contribuíram para uma leitura reduzida à forma-aparência imediata, generalizando as expressões carência e ausência como definidoras das condições de vida nas comunidades populares. Tais pressupostos reduziram (e ainda reduzem) as favelas à condição de territórios precários, ilegais, inacabados, desordenados e inseguros: o avesso da cidade. Assim, as leituras estereotipadas fazem das favelas territórios ilegítimos nas cidades e, por extensão, os seus moradores como pessoas incapazes de mudar as suas condições de existência, daí imersos no "círculo vicioso da pobreza".

Outro elemento recorrente da representação das favelas é a homogeneização. Presentes em diferentes sítios geográficos - planícies, morros, às margens de rios, 
manguezais e lagoas - e constituídas por diferentes formas de moradia, as favelas são a expressão de territórios marcados pela diversidade de práticas sociais e culturais. A homogeneidade, porém, é a tônica quando se trata de identificá-las de modo genérico e apressado.

Embora as favelas não sejam homogêneas, é inegável que há em muitas delas comunidades que experimentam condições precárias de existência urbana, sobretudo em termos da presença de serviços básicos de saneamento, ou mesmo em função da qualidade da edificação construída e da localização de suas moradas em termos de sensibilidade ambiental aos desmoronamentos e às enchentes. Acrescenta-se à situação de vulnerabilidade territorial, o domínio coercitivo e violento (e os recorrentes conflitos daí advindos) de grupos criminosos armados (narcotraficantes e milícias) em diversas comunidades.

A realidade social das favelas expressa as condições profundas de desigualdade, quando observamos as elevadas taxas de desemprego e subemprego presentes nestes territórios, demonstrando a particular condição de inserção de seus jovens e adultos no mundo do trabalho formal. Por outro lado, a situação de vulnerabilidade social apresenta-se com diversas faces nos espaços populares, sobretudo entre os jovens: baixa escolaridade, gravidez precoce, rendas ínfimas, subnutrição e vitimização em atos de violência.

Entretanto, não devemos tomar a situação de vulnerabilidade social em si mesma. Ou pior, tomar a favela como território da pobreza e da carência per si. Mas sim identificar em tais situações a reprodução territorial das condições de desigualdade social. As favelas expressam, em nosso modo de ver, as contradições e conflitos da urbanização do território, e nos convocam a assumir movimentos de inovação teóricoconceitual e da prática de investigação das relações entre a produção do espaço urbano, a reprodução das desigualdades sociais e a distinção territorial de direitos.

Lembrar que o Brasil se destacou como o país onde o processo de urbanização do território foi o mais veloz durante a segunda metade do século XX, não é demais. A população urbana em 1950 era 36\% da população total. Em cinco décadas (2000) ela já alcançava $81 \%$. Atualmente, como nos informa o Censo 2010 do IBGE, contamos com $84,35 \%$ da população residindo em cidades. De um país de características populacionais agrárias, o Brasil se tornou, de forma rápida, predominantemente urbano no curso de cinco décadas. 
Esse processo conheceu seu momento decisivo na década de 1970, quando a população urbana começou a superar a rural (56\% contra $44 \%)$, em função das fortes migrações na direção dos principais centros urbanos. Toda essa mudança trouxe novas dimensões para questão da habitação nas cidades, especialmente para as grandes cidades que se tornavam maiores com a concentração de empresas privadas e estatais. Destacando-se neste processo as metrópoles localizadas na Região Sudeste (São Paulo, Rio de Janeiro, Belo Horizonte).

Nesse meio século de urbanização acelerada, o número de domicílios passou de dois milhões para aproximadamente quarenta milhões, acompanhando o crescimento da população em geral e da urbana em particular. Entretanto, apenas 20\% dessas moradias fizeram parte direta da construção e do financiamento por parte dos governos (federal, estaduais e municipais) e de suas agências de fomento. A população construiu suas residências com seus próprios recursos diante da insuficiência das políticas estatais de habitação e do desinteresse do mercado formal, face às demandas das "populações de baixa renda".

Por outro lado, os investimentos em infraestrutura e serviços urbanos, empreendidos pelo Estado, foram amplos em espaços de interesse de empresas, imobiliários e bancários, beneficiando diretamente as classes de maior renda. $\mathrm{O}$ capital imobiliário e bancário teve, portanto, um papel decisivo na conformação das nossas cidades, pois foram os seus interesses que conduziram a estruturação urbana e a distribuição residencial das classes sociais. A atuação concentradora e especulativa do capital imobiliário, retendo áreas centrais urbanizadas e terras urbanizáveis à espera de valorização, implicou aos trabalhadores pobres a ocupação de sítios geomorfológicos, com riscos consideráveis (encostas íngremes, margens de rios, planícies inundáveis), de lotes e áreas urbanas destituídas de serviços básicos, e, no limite extremo, na periferia urbano-rural, sem qualquer infraestrutura básica, inclusive as de saneamento.

Atualmente estima-se um déficit de oito milhões de residências urbanas como resultante de uma urbanização tão igualmente acelerada como discricionária. Todavia, o déficit habitacional precisa ser considerado para além das demandas de unidades residenciais, uma vez que está associado a todo um conjunto de condições urbanas básicas de existência social (saneamento, regularização imobiliária e fundiária, distribuição territorial de serviços de saúde e educação), fazendo de nossas cidades máquinas de reprodução de desigualdades sociais e de distinções territoriais de direitos. 
As favelas são expressões estruturais do processo discricionário que caracteriza a urbanização do território brasileiro. É importante sublinhar que não se limitam a um fenômeno que se faz presente nas metrópoles do sudeste urbanizado, ou de uma realidade exclusiva de metrópoles nacionais e regionais. As favelas se fazem presentes como um fenômeno da urbanização do território brasileiro, inclusive marcando sua presença em diversas cidades médias, com um crescimento mais expressivo do que o observado em capitais, em especial as da Região Sudeste do país. Ou seja, o que queremos afirmar é que as favelas se fazem presentes tanto em processos de urbanização concentrada, como nos que são considerados como expressões da urbanização difusa.

O crescimento e a expansão de favelas são os produtos mais contundentes da urbanização desigual do território em destaque. Combinando dialeticamente o movimento de constituir-se como produto da concentração de capital, da propriedade privada e do poder político, que controla e fragmenta o espaço urbano e, contraditoriamente, significar uma estratégia de habitação da cidade pelos homens e mulheres mais profundamente marcados pela desigualdade social.

Apesar das leituras que sempre consagraram uma pretensa homogeneidade dos espaços populares, as favelas são complexas e muito diferentes entre si. Para além das particularidades de sua morfologia e localização, há também uma composição diferenciada de formas de trabalho, níveis de renda, de inserção ao consumo de bens e de acesso aos serviços públicos urbanos. Portanto, a pretensa anomia que caracterizaria a vida das/nas favelas significa uma negação das práticas plurais, que configuram as lutas populares para habitar as cidades. Os moradores das favelas possuem históricos complexos e relevantes atos de resistência contra desapropriações e remoções, conjugam estratégias diversas para conquistas de equipamentos e serviços urbanos (mesmo que precários e insuficientes) e inventam formas particulares de proteção e solidariedade.

Esses esforços conjugados de construir abrigos para si e suas famílias, realizados pelos trabalhadores subalternizados da cidade, nunca foram devidamente reconhecidos pela sociedade, nem pelo próprio Estado. Suas obras territorializadas sempre foram interpretadas e tratadas como ilegais, irregulares, informais, subnormais, precárias e clandestinas, por não obedecerem aos padrões racionais de edificação, por terem se 
constituído sem o crivo do controle governamental e por não possuírem documentação escriturada de propriedade e, sobretudo, pela origem social e racial de seus habitantes.

A relação de distinção entre o que é concebido e percebido como dentro e fora da ordem urbana é expressa, de modo contundente, nas e pelas representações hegemônicas que, por sua vez, promovem uma hierarquização territorial preconceituosa e discriminante para com a favela e seus moradores. Isto é igualmente válido, como afirma Sodré (2000), para a redescrição intelectual (sígnica, conceitual, imagística) do outro posto em posição subalterna pelo mesmo hegemônico, respondendo amplamente pelas leituras generalizantes e limitadas a respeito das favelas. É nesse sentido que o processo de distinção no espaço urbano se apresenta como distanciamento ontológico (corpóreo e territorial) entre o mesmo hegemônico e o outro subalternizado, radicalmente descrito no binômio "asfalto/favela", como marcação de hierarquias entre seres humanos e de distribuição de direitos da cidadania.

Nessa perspectiva, durante todo o século XX, o Estado brasileiro e o carioca, em particular, apesar da forte presença na paisagem urbana, dos territórios favelados, não assume um papel regulador. Isso se explica pelo histórico caráter patrimonialista, que predominava nas práticas dominantes nessa instância, o que impedia sua constituição de forma republicana. Nesse sentido, os órgãos estatais existiam para atender os interesses dos grupos econômicos e políticos, dominantes da cidade. Logo, as forças policiais, por exemplo, tinham como função defender a "cidadela", onde os grupos sociais mais ricos viviam e circulavam. Não se afirmava um juízo democrático que considerasse o conjunto de moradores da cidade como membros da polis, quer dizer, como sujeitos plenos de direitos.

As favelas não só resultam dessa desigual apropriação social da cidade, como também são produtos de concepções e práticas distintivas de direitos fundamentais. Há uma hierarquização da cidadania no território urbano que, no seu limite extremo, conduz ao sitiamento discriminador e ações indiscriminadas de violência contra comunidades populares. Assim, ao contrário da expressão "cidade partida", de Zuenir Ventura, que se popularizou a partir da década de 90, o que temos, historicamente, é um "Estado Partido", voltado para atender às demandas específicas, inclusive no campo da segurança patrimonial dos grupos dominantes. Não houve, em nossa história, uma regulação sobre o cotidiano nas áreas dos trabalhadores mais pobres, negros e 
posteriormente migrantes, a não ser a ação discricionária e autoritária de contingentes policiais, que agiam de forma isolada.

Com efeito, as forças que dominaram historicamente o Estado construíram um projeto de cidade, na qual os trabalhadores das favelas não eram reconhecidos. Estes tiveram, portanto, que construir suas próprias formas de sociabilidades, formas estas que permaneceram, por longo tempo, subterrâneas, invisíveis aos olhos do conjunto da população carioca. Esta via apenas as formas paisagísticas que iam dominando os morros, áreas de mangues e outros espaços menos valorizados pelo mercado. No processo, esses territórios populares tornaram-se uma presença marcante no Rio de Janeiro, e no País, e se afirmaram como uma experiência de habitar, tipicamente contemporânea.

Numa observação mais atenta para a intensa vida social presente nas favelas, percebemos códigos, marcações e práticas de sociabilidade que configuram significados próprios e que explicitam identidades socioculturais. Quando são superados os préconceitos em relação à vida nas favelas é possível verificar que há acordos, regras e normas instituídas nas vivências de seus habitantes. Há modos de viver que afirmam a existência de grupos sociais na apropriação do território. Assim como podemos identificar usos do território, que a despeito de regras formais de ocupação, apresentam soluções simples e criativas para edificação de moradias em condições geomorfológicas complexas, assim como o modo particular de acessar os serviços urbanos básicos (água, esgoto, eletricidade).

Quando se trata das favelas, a habitação não se resume aos padrões hegemônicos de uso exclusivamente residencial. A casa na favela tem outro sentido. Isto porque a habitação, no cotidiano dos espaços populares, tem funções muito mais amplas do que uma simples residência. Uma delas está vinculada às oportunidades de geração de trabalho e renda. Nas favelas a habitação pode ter um puxadinho para frente ou para trás, fazendo surgir uma pequena mercearia, um bar ou um salão de beleza. Multiplicam-se as oficinas mecânicas, os depósitos de bebidas, lojinhas de roupas e lanhouses, atividades socioeconômicas intimamente associadas à habitação. São pequenos negócios de origem familiar, que se mantêm graças ao mercado local constituído na própria favela. Na esquina uma farmácia, em outra uma padaria. Ali um restaurante. Do outro lado um açougue. É desse modo que os moradores dos espaços 
populares enfrentam o desemprego, os baixos salários, a discriminação racial e inventam um mercado socialmente necessário de trabalho, de bens e de consumo.

Outra função central para a habitação é sua condição de ponto de reunião de diversos grupos familiares. De fato, rompendo com a lógica da habitação em núcleos familiares reduzidos, um imóvel na favela pode reunir diferentes domicílios, com diferentes tipos de arranjos familiares. Nesse quadro, por exemplo, a possibilidade de possuir uma laje abre grandes possibilidades em termos de herança familiar, reserva de valor econômico e espaço lazer, de congraçamento de grupos diversos. Cabe, nesse caso, reconhecer as formas plurais de organização familiar nas favelas, que rompem com as lógicas vigentes nos bairros dos setores médios, economicamente falando, da cidade.

Ao enunciar as suas especificidades, as favelas também revelam a sua inserção na vida da sociedade urbana. Podemos afirmar, inclusive, que as favelas representam a maximização das possibilidades econômicas, culturais e sociais, realizada pelos pobres, nos seus mais legítimos esforços para habitar a cidade. Mesmo nas mais precárias de suas configurações de habitação e serviços básicos, as favelas são territórios onde os pobres afirmaram sua presença no espaço urbano. Podemos afirmar então que, a favela é uma das mais contundentes expressões do estar sendo das desigualdades que marcam a vida em sociedade em nosso país, em especial nas grandes e médias cidades brasileiras. É nesse plano que as favelas devem ser tratadas, pois são territórios que colocam em questão o sentido da sociedade e da espacialidade urbana em que vivemos.

Todavia, são justamente esses territórios os mais vulneráveis diante das limitações e incompletudes das políticas sociais governamentais, da notória concentração de renda e propriedade urbanas, dos interesses exclusivistas do mercado e da criminalidade violenta. E, contraditoriamente, as favelas são expressões da afirmação cotidiana do viver e do inventar a cidade, como obra humana compartilhada. Ou como nos alerta Holston (1996, p.249/50) a respeito da emergência de espaços insurgentes: (...) porque introduzem novas identidades e práticas que perturbam histórias estabelecidas.

As diferentes comunidades urbanas, que se fazem como favelas em seu processo legítimo de habitar a cidade, possuem diferentes marcações simbólicas e movimentos de pertencimento ao território usado, protagonizando modos particulares de permanência de grupos populares no espaço urbano. 
Ao colocarmos em causa os territórios de existência de grupos populares não estamos nos referindo simplesmente a um abrigo individual e familiar. Falamos do território de usos plurais, onde determinados grupos marcados pela proximidade de valores, práticas, vivências, memórias e posição social constroem experiências tangíveis e intangíveis como força de realização das suas vidas. Estas não estão situadas em qualquer ponto ou área da cidade, mas sim em uma experiência territorial corpórea, que reúne qualidades materiais (acessibilidade a bens, serviços e renda) e simbólicas (compartilhamentos socioculturais) produzidas, classificadas e mobilizadas pelos seus membros, definindo o quadro de relações intersubjetivas de aproximação social na realização de possibilidades objetivas de existência. Explica-se assim, porque os processos de remoção de favelas, colocados em prática pelo Estado e pelo mercado, significam um modo perverso de expropriação de experiências de sociabilidade urbana.

Entretanto, longe de representarem territórios caóticos, sem lei e sem controle, que ameaçam a cidade - como afirmam os discursos mais conservadores - as favelas constituem experiências valiosas para repensar e refazer a cidade como um todo. As favelas são, na verdade, uma das expressões de maior vitalidade da vivência cotidiana dos pobres, em um permanente processo de resignificar a cidade.

Estamos diante de processos complexos de identificação como um ato de pertencer àquilo que nos pertence (SANTOS: 2002). Podemos considerar o sentido de pertencer como uma associação entre a representação e a experiência, capaz de articular comportamentos, saberes e conhecimentos individuais e coletivos.

O território não é apenas um lugar físico que se habita. É uma experiência de comunicação entre sujeitos sociais. E, em se tratando de espaços populares, por mais precária que se nos apresente a sua forma-aparência, não podemos desconsiderar as vivências compartilhadas pelo grupo social, que os animam com suas histórias e, por meio destas, possibilitam que os indivíduos e grupos sociais se posicionem no mundo. Emergem desse movimento homens e mulheres que superam os estigmas sociais e raciais que lhes são impostos. Pessoas que não necessitam somente, mas que sonham, desejam e exigem direitos.

Logo, cabe aos profissionais que atuam nos territórios favelados, em particular, considerando os objetivos do presente artigo, os arquitetos e urbanistas, abrir-se para um olhar plural sobre as favelas e seus moradores. E, nesse processo, buscar apreender suas práticas, suas criações, inventividades e processos constitutivos de forma 
respeitosa e aberta. Cabe ir além dos juízos tradicionais e buscar contribuir para que essa rica construção socioterritorial seja preservada e, ao mesmo tempo, garantir condições efetivas para a melhoria permanente da qualidade de vida desses cidadãos. $\mathrm{O}$ desafio é abrangente, profundo e acima de tudo necessário.

\section{Referências Bibliográficas:}

BARBOSA, Jorge Luiz. Modernização Urbana e Movimento Operário. Rio de Janeiro: Programa de Pós-Graduação em Geografia. UFRJ, 1990.

HOLSTON, J. Espaços de cidadania insurgente. In Revista do Patrimônio Histórico Artístico e Cultural. N ${ }^{a}$ 24. IPHAN. Ministério da Cultura. 1996

LEEDS, Anthony \& LEEDS, Elizabeth. A sociologia do Brasil urbano. Rio de Janeiro: Zahar, 1978.

PARISSE, L. Favelas do Rio de Janeiro: evolução-sentido. Rio de Janeiro: Caderno do CENPHA, n.5, 1969.

PERLMAN, Janice: $O$ mito da marginalidade. Ed. Zahar. $2^{\text {a }}$ Ed. 1980.

SANTOS, Milton. O retorno do território. In: SANTOS, M., SOUZA, M. A. A. de, SILVEIRA, M. L. Território: globalização e fragmentação. São Paulo: Editora HUCITEC, 1994.

SANTOS, Milton. O território e o dinheiro. In Territórios e Territórios. Niterói: PPGEO - UFF, DP\&A Editora, 2002.

SODRÉ, Muniz A. C. Claros e Escuros. Vozes: Rio de Janeiro, 2000

SOUZA E SILVA, Jailson de, e BARBOSA, Jorge Luiz (org). O que é a favela, afinal? Rio de Janeiro: Observatório de Favelas/BNDES, 2009

SOUZA E SILVA, Jailson de, e BARBOSA, Jorge Luiz. Favela: alegria e dor da cidade. São Paulo/ Rio de Janeiro: SENAC / X - Brasil, 2005.

VALADADARES, Lícia. Passa-se uma casa. Ed. Zahar. 2a ed, 1980.

VENTURA, Zuenir. Cidade partida. Rio de Janeiro: Companhia das Letras, 1995. ALVITO, Marcus e ZALUAR, Alba (Org). Um século de favela. Rio de Janeiro: Fundação Getúlio Vargas, 1998. 